\title{
A FASE DE PRÉ-INSTITUCIONALIZAÇÃO DO PROGRAMA DE APOIO AO INTERCAMBISTA (PAI) E OS ENTRAVES À SUA OBJETIVAÇÃO
}

THE PRE-INSTITUTIONALIZATION PHASE OF THE EXCHANGE STUDENT SUPPORT PROGRAM (PAI)

AND THE BARRIERS TO ITS ACHIEVEMENT

\section{LA FASE DE PREINSTITUCIONALIZACIÓN DEL PROGRAMA DE APOYO AL ESTUDIANTE DE INTERCAMBIO (PAI) Y LAS TRABAS A SU OBJETIVACIÓN}

ITALO CAVALCANTE AGUIAR

Mestre

Universidade Federal do Ceará - Brasil

ital0474@gmail.com

ORCID: https://orcid.org/0000-0002-6419-5551

BARBARA SAMPAIO DE MENEZES

Mestra

Universidade Federal do Ceará - Brasil

barbarasampaiodemenezes@gmail.com ORCID: https://orcid.org/0000-0002-2058-1629

BRUNO DE SOUZA LESSA

Doutorando

Universidade Federal do Rio Grande do Sul - Brasil

brunolessa85@yahoo.com.br

ORCID: https://orcid.org/0000-0002-1696-394X

AUGUSTO CEZAR DE AQUINO CABRAL

Doutor

Universidade Federal do Ceará - Brasil cabral1@ufc.br ORCID: https://orcid.org/0000-0001-8248-4886

SANDRA MARIA DOS SANTOS

Doutora

Universidade Federal do Ceará - Brasil smsantosufcc@gmail.com ORCID: https://orcid.org/0000-0002-8515-9146

Submetido em: 04/09/2017

Aprovado em: 20/02/2019

Doi: alcance.v25n3(Set/Dez).p315-329

\section{RESUMO}

O Programa de Apoio ao Intercambista (PAl) é pertencente à Faculdade de Economia, Administração, Atuária e Contabilidade (FEAAC) da Universidade Federal do Ceará (UFC) e tem o objetivo de ajudar e guiar estudantes de mobilidade acadêmica internacional na UFC nos seus primeiros momentos em Fortaleza, fornecendo apoio e incentivando trocas de experiências entre os acadêmicos estrangeiros e os da UFC. 0 presente estudo tem 0 objetivo de analisar os fatores que configuram o programa na fase de pré-institucionalização. A presente pesquisa 
é de abordagem qualitativa. Quanto aos fins, esta pesquisa é descritiva e quanto aos meios é documental e um estudo de caso sobre o PAI. Já a apreciação dos dados coletados foi feita por meio da análise de conteúdo. A pesquisa contribui com aprofundamento do processo de institucionalização do suporte ao estudante estrangeiro em uma universidade brasileira, temática pouco difundida e explorada em pesquisas nacionais até então. Concluiu-se que houve uma evolução dos fatores que determinaram a fase de pré-institucionalização do programa; percebeu-se que um dos principais fatores que causa entraves à fase de objetivação dele é a falta de uma estrutura física e constatou-se que um dos fatores que coadjuva à fase de objetivação é o monitoramento por meio da comparação com o suporte aos estudantes estrangeiros feito por outras universidades brasileiras ou estrangeiras. Como limitações da pesquisa, identifica-se o número de entrevistados e sugere-se que sejam abordadas as perceptivas dos professores, dos servidores e dos gestores em pesquisas futuras.

Palavras-chave: Teoria Institucional; Internacionalização; Estudantes.

\section{ABSTRACT}

The Exchange students Support Program (PAI) belongs to the Faculty of Economics, Administration, Actuarial and Accounting (FEAAC) of the Federal University of Ceará (UFC) and aims to help and guide international academic mobility students in the UFC during their first Moments in Fortaleza, providing support, and encouraging the exchange of experiences between the exchange students and the regular students of UFC. This study aims to analyze the factors that configure the program in the pre-institutionalization phase, according to the model of Tolbert and Zucker (1999). The following specific criteria were established: i) to verify the evolution of the determining factors in the verification of the pre-institutionalization phase of the program over the three years; ii) to identify the obstacles to progress in the objectification phase and iii) to verify the factors that contribute to the objectification phase of the program. This research has a qualitative approach. Regarding the outcomes, it is exploratory, and in relation to means, it is descriptive, with field and document research. The data collected was analyzed using Bardinn's (2016) content analysis. The research contributes with a deepening of the process of institutionalization of support for foreign students at a Brazilian University, a subject with little dissemination or exploration in the national research so far. It is concluded that there was an evolution of the factors that determined the preinstitutionalization phase of the program. It was observed that one of the main factors that poses obstacles in the objectification phase of the program is the lack of a physical structure, and that one of the Factors that contribute to the objectification phase is monitoring through comparison with the support for foreign students offered by other Brazilian or foreign universities. In terms of limitations of the research, the number of interviewees was small, and future research, a suggestion would be to investigate the perceptions of teachers, civil servants and managers on the subject.

Keywords: Institutionalization; Internationalization; Students.

\section{RESUMEN}

El Programa de Apoyo al Intercambio (PAl) es perteneciente a la Facultad de Economía, Administración, Actuaria y Contabilidad (FEAAC) de la Universidade Federal do Ceará (UFC) y tiene el objetivo de ayudar y guiar estudiantes de movilidad académica internacional en la UFC en sus primeros momentos en Fortaleza, forneciendo apoyo e incentivando intercambios de experiencias entre los académicos extranjeros y los de la UFC. El presente estudio tiene el objetivo de analizar los factores que configuran el programa en la fase de pré-institucionalización. La presente investigación es de abordaje cualitativo. En relación a los fines, esta investigación es descriptiva y cuanto a los medios es documental y un estudio de caso. Ya la apreciación de los datos colectados fue hecha por medio de análisis de contenido. La investigación contribuyó profundamente con el proceso de institucionalización del soporte al estudiante extranjero en una universidad brasileña, temática poco difundida y explorada en investigaciones nacionales hasta ahora. Se concluye que hubo una evolución de los factores que determinaron la fase de pré-institucionalización del programa; se percibió que uno de los principales factores que causa traba a la fase de objetivación de este es la falta de una estructura física y se constató que uno de los factores que coadyuva a la fase de objetivación es el monitoreo por medio de la comparación con el soporte a los estudiantes extranjeros hecho por otras universidades brasileñas o extranjeras. Como limitaciones de investigación, se identifica el número de entrevistados y sugiere que sean abordadas las perceptivas de los profesores, de los servidores y de los gestores en investigaciones futuras.

Palabras-clave: Teoría Institucional; Internacionalización; Estudiantes. 


\section{INTRODUÇÃO}

Emergindo novas questões relativas à mobilidade estudantil, a tendência da globalização tem versado sobre o intercâmbio como um fenômeno universal na sociedade moderna. Com isso, as instituições que recebem esses estudantes estão precisando se adequar a esse novo tipo de mobilidade internacional. Não obstante, baseado em experiências de admissão e acolhimento de alunos estrangeiros, denotam-se algumas dificuldades de adaptação e os desafios enfrentados pelos mesmos, tais como o desenvolvimento de estratégias institucionais para enfrentar esses problemas, as quais são analisadas por meio de fatores críticos e o contato com experiências de um mundo e cultura estranhos (Peña \& Soares, 2017; Wen Yu, 2009; Silveira, 2017).

Embora alguns países estejam atraindo uma grande quantidade de estudantes estrangeiros, o número de pesquisas sobre a adaptação às universidades e as experiências desses alunos ainda permanece escassa. Concomitante a isso, as universidades têm registrado um crescimento substancial na demanda de estudantes estrangeiros, lidando ainda com a diversidade e com os desafios multifacetados encontrados por ambas as partes (Andrade \& Teixeira, 2009; Nada \& Araújo, 2018).

Dessa forma, assim como a natureza da inclusão educacional apresenta parâmetros complexos com questões de poder, o processo de globalização é caracterizado pelas tendências da mistura intercultural e da troca de estudantes. Com isso, as universidades expressam preocupação com o aconselhamento e 0 acompanhamento, já que afeta de forma evidente ou sutil a experiência do aluno (Naidoo, 2018; Ibragimova \& Tarasova, 2018).

De acordo com Silveira (2017, p. 1), ressalta-se que "as particularidades decorrentes do processo adaptativo do estudante internacional sugerem, de acordo com a literatura, a necessidade de serviços direcionados especificamente para o estudante estrangeiro". Com isso, o presente estudo justifica-se por fomentar questões relativas à ausência e à necessidade do suporte ao estudante estrangeiro, e como se dá a institucionalização de projetos, versando as fases da institucionalização e os entraves para a objetivação do programa. Assim, este trabalho se desenvolve em torno do seguinte problema de pesquisa: Quais os fatores que determinam a fase de Pré-institucionalização do Programa de Apoio ao Intercambista?

Nessa conjuntura, apresenta-se o Programa de Apoio ao Intercambista (PAI), que auxilia e orienta estudantes de mobilidade acadêmica internacional na UFC nos seus primeiros momentos em Fortaleza, na qual incentiva a troca de experiências culturais e acadêmicas entre estudantes da UFC e estudantes oriundos de universidades estrangeiras. Ainda assim, a teoria institucional apresenta vários modelos do processo de institucionalização de uma determinada estrutura na organização, dentre eles o de Tolbert e Zucker (1999), sendo esse processo o meio da inserção do objeto de estudo na teoria institucional e seus modelos estruturados.

0 presente trabalho está estruturado em cinco seções: esta Introdução, contendo objetivos, problema de pesquisa e justificativa; a segunda seção, que consiste na Fundamentação Teórica, contemplando sobre teoria institucional e modelo de institucionalização de Tolbert e Zucker (1999). Já a terceira seção aborda os Procedimentos Metodológicos, que foram realizados explanando sobre o objetivo da pesquisa, natureza, local de realização e técnica de coleta e análise dos dados. Em seguida, apresenta-se a Análise dos Resultados e, por fim, apresentam-se as Considerações Finais do estudo.

\section{REFERENCIAL TEÓRICO}

Nesta seção é abordado sobre a teoria institucional, o modelo de institucionalização, além das fases desse processo de institucionalização.

\subsection{A Teoria Institucional}

Na percepção de Moraes (2001), a institucionalização é o processo pelo qual os grupos sociais se estabelecem nas organizações e conseguem com o tempo fornecer um conjunto de padrões de comportamento e regras aos seus membros e aos demais membros da organização aceitas como algo que prevalece e permanece dando estabilidade e previsibilidade às ações dos indivíduos na organização. $O$ autor retrata ainda que, após extenso estudo de várias definições de instituição social, ele a define como um: "conjuntos de regras e restrições que governam as relações sociais entre indivíduos ou grupos, emprestando a essas relações uma certa estabilidade e previsibilidade". Empresas legalmente constituídas, nessa acepção, podem ser consideradas "instituições", pois fornecem um conjunto de regras e restrições que moldam tanto as relações entre seus membros 
(indivíduos) como entre estes e outras organizações.

Segundo Burns (2000), as rotinas incluem um comportamento programático baseado em regras, o qual está fundamentado em repetidamente seguir tais regras formais ou informais. Com o passar do tempo, as rotinas se tornam crescentemente suportadas por conhecimento tácito que os indivíduos adquirem pela monitoração reflexiva do comportamento passado.

Visto que Selznick (1996) menciona que a interação entre cultura e organização é mediada por uma mente socialmente construída, os padrões de percepção e avaliação vão contra a perspectiva racionalista do homem, segundo a qual este realiza suas escolhas de modo totalmente consciente. Mesmo quando ocorre a coerção, ainda há a interpretação cognitiva e sua estabilização no plano normativo. Dessa forma, DiMaggio e Powell (2005) acrescentam que o denominado novo institucionalismo apresenta uma perspectiva cognitiva e cultural para a explicação dos fundamentos da ação social.

Para Vieira e Carvalho (2003), a abordagem institucional diferencia-se de teorias de caráter racionalista por entender que o ambiente institucional (política, economia, cultura, etc.) molda as crenças, os valores e as ações do indivíduo. Como as instituições são resultado da construção humana, pode-se mencionar que o processo institucional é estruturado e estruturante simultaneamente, não sendo necessariamente racional e objetivo, mas sim fruto de interpretações e da intersubjetividade. Quando essas interpretações servem a uma finalidade específica, passando a ter utilidade e sendo amplamente compartilhadas, adquire-se caráter racional.

De acordo com Berger e Luckmann (1996), as condutas institucionalizadas envolvem certo número de papéis que participam do controle da institucionalização. Esses papéis representam a ordem institucional, que se realiza em dois níveis: a execução do papel representa a si mesma e o papel representa uma completa necessidade institucional de conduta. Suas origens encontram-se nos mesmos processos de formação dos hábitos e da objetivação, e toda conduta institucionalizada envolve certo número de papéis que participa do caráter controlador da institucionalização, representando a ordem institucional. Conforme o papel que o indivíduo realiza na sociedade, ele constrói "um apêndice socialmente definido de conhecimentos". Ainda, para os mesmos autores, quanto maior for o compartilhamento das estruturas importantes de uma sociedade, mais ampla será a esfera da institucionalização. Quando menor, a esfera da institucionalização será estreita e possivelmente fragmentada. Já para Scott (2001), a pressão para a institucionalização varia de acordo com o tamanho da organização, pois pode haver uma autoridade supervisora em sua jurisdição que a leve a institucionalizar mais rapidamente certas práticas. Berger e Luckmann (1996) ainda ressaltam que as pessoas fazem as coisas não porque estas dão resultados, mas porque são certas, mesmo que sob a percepção de um observador externo tais atos não sejam mais úteis à sociedade.

A legitimação produz novos significados que integram os significados já existentes nos processos institucionais, principalmente nos casos em que a origem real das sedimentações perdeu importância, e explica a ordem institucional, dando validade cognitiva aos significados objetivados, dando dignidade normativa aos imperativos práticos e implicando valores e conhecimento. Sua função é tornar objetivamente acessíveis e subjetivamente plausíveis as objetivações que foram institucionalizadas (Berger \& Luckmann, 1996)

Aqueles que detêm o poder podem trabalhar com uma considerável resistência à institucionalização de uma mudança social, pois quando eles possuem os recursos e a mudança vem a alterar a ordem vigente, esses atores não participarão da nova ordem e farão o possível para essas mudanças não ocorrerem. Ao se considerar o aspecto interpretativo, observa-se que, juntamente com a dominação, a legitimidade constitui o poder, uma vez que esse poder precisa de uma sustentação social cognitivo-normativa que o explique. Essa legitimidade será depois utilizada pelos atores para se manterem no poder (Machado da-Silva, Fonseca \& Crubellate, 2005; Beckert, 1999). Para se ter ideia do alcance desse poder, é importante lembrar que todos os sistemas sociais, assim como as organizações, estão em um ambiente institucional que delimita sua realidade (Scott, 1987).

\subsection{Modelo de Institucionalização de Tolbert e Zucker (1999)}

Uma alternativa à concepção de ação social tradicional na análise organizacional, na qual a decisão deveria ser concebida por critérios racionais de escolha, é feita por meio da abordagem institucional (Quinelo, 2007). Essa perspectiva inaugura uma nova forma de pensar a temática das instituições, que passam a ser estudadas como sendo fundamentalmente constituídas e moldadas por regras, classificações, esquemas e rotinas que assumem um papel simbólico na estrutura formal e que decorrem do hábito e das tipificações que são socialmente definidas e partilhadas num contexto abrangente (Ferreira, Casaca \& Jerônimo, 2001).

Italo C. Aguiar, Barbara S. de Menezes, Bruno de S. Lessa, Augusto Cezar de A. Cabral e Sandra M. dos Santos 
A abordagem institucional é dividida, tradicionalmente, em duas escolas, a "velha" e a "nova" escola institucionalista (Quinelo, 2007). Greenwood et al. (2007) dividem essa segunda escola em quatro períodos: fundações, de 1977 a 1983; primeiros anos, de 1983 a 1991; "fazendo balanço", de 1987 a 1991; e expandindo os horizontes, a partir de 1991 até os dias atuais.

No primeiro período as organizações passam a ser consideradas como influenciadas por seus contextos institucionais e rede de relacionamentos (Greenwood, 2007). Esse contexto institucional consiste em mitos racionalizados de conduta apropriada, sendo esses mitos manifestações de poderosas regras institucionais como programas e procedimentos impostos pela opinião pública, pelas concepções de importantes agentes, pelo prestígio social ou pelas leis (Ferreira, Casaca \& Jerônimo, 2001).

Desse período, destaca-se a obra de Zucker (1977), que parte da percepção que as formas tradicionais de institucionalização não conseguem explicar a persistência cultural. Dessa forma, a autora utiliza uma abordagem etno-metodológica, em que os atores individuais transmitem uma realidade, que tem como características a objetividade e a exterioridade, e ao mesmo tempo essa realidade define o que é real para esses mesmos atores devido àquelas qualidades.

Consequentemente, Zucker (1977) define a institucionalização como um processo no qual atores individuais transmitem o que é socialmente definido como real e, ao mesmo tempo, em algum ponto desse processo, o significado de um ato pode ser definido como mais ou menos um fato "dado como certo" de uma realidade social. Assim, atos institucionalizados devem ser percebidos como objetivos e externalizados. A autora acrescenta que existem três aspectos da persistência cultural que são afetados diretamente pelo grau de institucionalização de um ato, são eles: a transmissão, a manutenção e a resistência a mudanças.

Assim, a partir de estudos anteriores, Tolbert e Zucker (1999) desenvolvem um modelo do processo de institucionalização, conforme Figura 1, composto de três processos sequenciais:

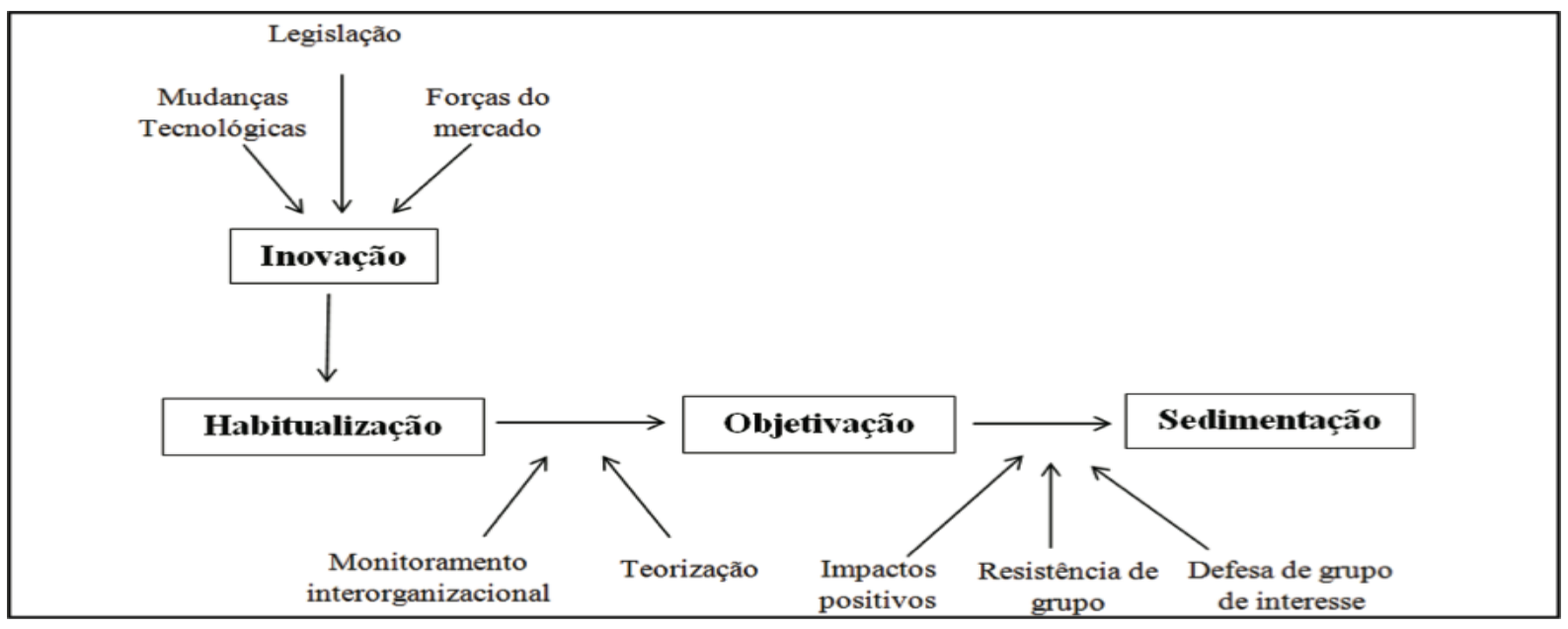

Figura 1: Processo de Institucionalização

Fonte: Adaptado de Tolbert e Zuckert (1999).

a) Habitualização: Envolve a criação de configurações estruturais em resposta às demandas específicas do contexto em que a organização se insere, assim como a formalização dessas configurações na organização, ou no conjunto de organizações que possuem similaridades. As estruturas resultantes desse processo são classificadas como pertencentes de um estágio de préinstitucionalização. Nesse estágio, a adoção de uma dada estrutura é limitada a um pequeno grupo de organização, que possui características similares e varia em termos da forma como é implementada.

b) Objetivação (ou objetificação): Envolve o desenvolvimento de um consenso entre os adotantes a respeito do valor da estrutura, além da sua adoção crescente com base nesse consenso que emerge por meio de dois mecanismos: o monitoramento, realizado pela organização nos seus concorrentes, o qual avalia os riscos de adoção de uma nova estrutura; a teorização, que atribui à estrutura uma legitimidade cognitiva e normativa geral. As estruturas que passaram por esse processo podem ser 
descritas como estando no estágio de semi-institucionalização.

c) Sedimentação: Caracteriza-se pela propagação da estrutura por um grupo de atores, considerados como adotantes adequados, e por sua perpetuação por um período consideravelmente longo de tempo, sendo considerado o estágio de total institucionalização. Alguns fatores afetam esse processo de difusão e conservação de uma estrutura. Um dos fatores é a existência de um conjunto de atores que se mobilizam contra ela, por serem afetados negativamente, a existência de conflito de interesses e a falta de evidências relacionando resultados positivos à estrutura.

Sobre a fase da habitualização é importante ressaltar que essa pré-institucionalização está relacionada à adoção de semelhantes inovações como implicação de estarem contidas em um mesmo contexto organizacional. Conforme Tolbert e Zucker (1999), isso se torna a chamada "invenção simultânea", cujas organizações distintas aceitam o mesmo processo de forma concomitante.

Isso, segundo Dimaggio e Powell (1991), pode ser levado ao entendimento de isomorfismo ou imitação, ou seja, uma organização aborda sobre soluções desenvolvidas por outras em virtude de três fatores ou de uma combinação entre eles:

I) Coercitivo (influência política e da necessidade de legitimação): as organizações são submetidas a pressões externas, formais ou informais, vindas de outras das quais são dependentes ou em virtude de expectativas culturais da sociedade.

II) Mimético (padronização de respostas à incerteza): ocorre quando uma organização imita práticas de outra, por conta das incertezas ambientais, correspondendo a um processo de reprodução ou imitação de políticas, estratégias, estruturas, tecnologias, sistemas produtivos, produtos, serviços e práticas administrativas em geral.

III) Normativo (profissionalização): derivado do estabelecimento de padrões por uma determinada comunidade profissional, com vistas a embasar cognitivamente e dar legitimidade à atividade por ela desenvolvida.

Por sua vez, Souza (2010) ressalta que existem três fatores essenciais que levam as empresas a inovarem ou identificarem essa necessidade de inovar, que são eles: I) mudanças tecnológicas, ou melhor reorientação técnica ou tecnológica; II) legislação, representando novos arranjos jurídicos que podem provocar maior ou menor receptividade por parte das organizações; e III) forças do mercado, decorrentes de fatores econômicos. Estes três fatores levam a organização à inovação e, por consequência, a um processo de habitualização.

Já na fase de objetificação, há uma passagem do estágio pré-institucional para o semi-institucional, que, conforme Tolbert \& Zucker, 1999, p. 207, se dá pelo "desenvolvimento de certo grau de consenso social entre os decisores da organização a respeito do valor da estrutura e a crescente adoção pelas organizações com base neste consenso". Esse estágio é, em parte, decorrente da "sequência de monitoramento que a organização faz dos seus competidores, e de esforços para aumentar sua competitividade relativa".

Nesta etapa, primeiramente, identifica-se um problema de insatisfação ou de fracasso organizacional, típico de um determinado campo organizacional e de reconhecimento público; em seguida, teorias são desenvolvidas de modo "[...] que diagnostiquem as fontes de insatisfação ou de fracasso, de modo compatível com a apresentação de uma estrutura específica como solução ou tratamento" (Tolbert \& Zucker, 1991, p. 208-209).

Por fim, na fase de sedimentação, a de institucionalização total, conforme Souza (2010) aborda sobre duas dimensões: 1) a propagação das estruturas para todos os indivíduos teorizados como adotantes; e 2) a perpetuação dessas mesmas estruturas ao longo de um tempo consideravelmente longo. Para que o processo de institucionalização seja total, é preciso que sejam identificados alguns fatores que afetam tanto a difusão quanto a conservação ao longo do tempo das estruturas. Assim, Tolbert e Zucker (1999) identificam três fatores principais para o processo de institucionalização ser total: I) impactos positivos - resultados demonstráveis associados à estrutura; II) resistência de grupo - pessoas que são afetadas adversamente pela estrutura; e III) defesa de grupo de interesse - pessoas que são favoráveis às mudanças na estrutura. Dessa maneira, nota-se que o processo de institucionalização proposto por Tolbert e Zucker (1999) é um conjunto de fatores que pode motivar se uma mudança organizacional será ou não bem-sucedida. 
Este modelo proposto por Tolbert e Zucker (1999) foi utilizado por Lima et al. (2011, p. 90) para estudar o processo de institucionalização das práticas de responsabilidade social na Companhia de Água e Esgoto do Ceará (CAGECE), concluindo que o processo "ainda está em andamento, com progressos moderados, mas com mudanças a serem formalizadas, sistematizadas, consolidadas e disseminadas".

Lima et al. (2012, p. 14), por meio desse modelo, analisaram o processo de institucionalização da economia criativa do humor no Estado do Ceará que, segundo indicam os resultados, "está, atualmente, entre as fases de objetificação e de sedimentação, pois as recentes estruturas ainda não foram perpetuadas e sua teorização formal ainda não ocorreu".

Penha et al. (2013, p. 1), utilizando tal modelo de institucionalização para investigar o processo de institucionalização das empresas juniores (EJs) das universidades públicas do Ceará, chegaram ao resultado indicativo que "as EJs estão entre as fases de objetificação e sedimentação".

\section{METODOLOGIA}

A presente pesquisa é desenvolvida mediante abordagem qualitativa, que possibilita ao pesquisador identificar as motivações que levam os atores sociais ao exercício de suas práticas socioespaciais, sendo o mais importante a fundamentação de elementos que sustentem a produção de um discurso capaz de representar 0 posicionamento de todo o segmento social. A história desse segmento, associada à própria contextualização dos arranjos que envolvem a prática dos mesmos na atualidade, confere o caráter científico desse método, uma vez que induz a necessidade de delinear os procedimentos necessários à investigação de tal forma que possibilite a própria compreensão das interpretações que os atores sociais possuem do mundo (Bauer \& Gaskell, 2002).

Assim, a abordagem qualitativa é utilizada por possibilitar uma análise de maior amplitude da observação do fenômeno institucional, admitindo fortes inferências do ambiente e das pessoas que dele participam, interagindo todos na constituição da realidade dos participantes do Programa de Apoio ao Intercambista (PAI). Dessa forma, justifica-se por quanto à relevância, a escolha das caracterizações capazes de diferenciar as pessoas detentoras de informações mais válidas e suficientes para compreensão da institucionalização do campo: a) tempo de atuação no Programa de Apoio ao Intercambista (PAl); b) conhecimento sobre as atividades realizadas pelo PAI e a evolução do programa nos últimos anos; c) cargo de atuação atual; d) acessibilidade.

Quanto aos objetivos ou aos fins, esta pesquisa é exploratória, por se adequar à caracterização de Collis e Hussey (2005) acerca deste tipo de pesquisa, ou seja, um estudo realizado "sobre um problema de pesquisa ou questão de pesquisa quando há pouco ou nenhum estudo anterior em que possamos buscar informações sobre a questão ou o problema". O processo de institucionalização de programas de suporte aos estudantes estrangeiros, conforme o mapeamento de literatura realizado, já foi especificamente objeto de um estudo específico. Observa-se que essa pesquisa avança com a continuidade do artigo "O processo de institucionalização do programa de apoio a estudantes de intercâmbio da Universidade Federal do Ceará", publicado em 2015 pela Revista Alcance.

Ainda quanto aos objetivos ou aos fins, este estudo também se caracteriza como descritivo, por expor características do fenômeno pesquisado, sem a obrigação de explicar o que foi descrito, ainda que esses resultados possam servir de base para explicações (Vergara, 2009). Por meio da descrição de fatos, características e comportamentos do campo dos assuntos internacionais da Universidade Federal do Ceará e do Programa de Apoio ao Intercambista (PAl), será alcançado o entendimento da evolução do seu processo de institucionalização.

Quanto aos procedimentos ou aos meios, utilizou-se do estudo de caso. Conforme Fonseca (2002, p. 33), "Um estudo de caso pode ser caracterizado como um estudo de uma entidade bem definida como um programa, uma instituição, um sistema educativo, uma pessoa, ou uma unidade social", levando em consideração a observação de três aspectos de verificação: a entrevista, a observação e a análise documental. No caso da pesquisa, foi realizado com o Programa de Apoio ao Intercambista (PAl). Já conforme critério de Gil (2002) e Vergara (2007), quanto ao seu aspecto documental, foram analisados os documentos do programa, divididos em dois períodos específicos: primeiro entre os anos de 2014-2015 e depois documentos relativos aos anos de 20162017.

Os documentos analisados no primeiro período são: lista de padrinhos, lista de estudantes estrangeiros, manual com as atividades do programa, editais dos processos seletivos do programa, manual com as atividades

Revista Alcance - Eletrônica - vol. 25 - n. 3 - Set./Dez. 2018 
a serem executadas pelos coordenadores do programa, apresentação do treinamento para os novos padrinhos, modelo de declaração de participação no programa, modelo de declaração de participação como coordenador do programa, roteiro das dinâmicas a serem realizadas no processo seletivo de novos padrinhos, planilha de feedback dos intercambistas, atas das reuniões, textos de divulgação do processo seletivo na internet.

No segundo período, os documentos analisados foram: planilha de acompanhamento das atividades dos padrinhos, planilha de acompanhamento dos intercambistas, planilha para as sugestões de ideias dos padrinhos, planilha para sugestão de ideias dos intercambistas, apresentação para a cerimônia de boas-vindas para os intercambistas em inglês, apresentação para a cerimônia de boas-vindas para os intercambistas em português, planilha de desligamento do programa, textos para a divulgação do processo seletivo no site da UFC, edital de seleção para coordenadores do programa, planilha para o controle de atividades dos coordenadores do programa, lista de padrinhos, lista de estudantes estrangeiros, manual com as atividades do programa, editais dos processos seletivos do programa, manual com as atividades a serem executadas pelos coordenadores do programa, apresentação do treinamento para os novos padrinhos, modelo de declaração de participação no programa, modelo de declaração de participação como coordenador do programa, roteiro das dinâmicas a serem realizadas no processo seletivo de novos padrinhos e atas das reuniões.

Essa divisão temporal foi feita com o objetivo de visualizar de maneira mais clara a evolução dos fatores que determinam a transição da fase de pré-institucionalização para semi-institucionalização do PAl de acordo com o modelo de Tolbert e Zucker (1999).

Os sujeitos da pesquisa foram escolhidos de forma não aleatória, considerando os critérios de relevância e acessibilidade. A escolha desses estudantes deve-se ao conhecimento sobre as atividades padronizadas e não padronizadas do PAl, já que atuaram como gestores dos processos do programa por um ano, como mostrado na Figura 2. Foram excluídas as pessoas que não dominavam os processos do PAl, pois não seria possível visualizar a evolução ou não do programa ao longo dos anos com a visão de um participante que não conhece todo 0 processo.

\begin{tabular}{|c|c|c|c|c|}
\hline Nome & Idade & Sexo & Vínculo com a UFC & Ingresso na Coordenação do PAI \\
\hline A1 & 23 & M & Estudante de graduação & 2015 \\
\hline A2 & 22 & F & Estudante de graduação & 2015 \\
\hline A3 & 25 & M & Estudante de graduação & 2015 \\
\hline A4 & 27 & M & Estudante de graduação & 2015 \\
\hline A5 & 22 & M & Estudante de graduação & 2015 \\
\hline A6 & 23 & F & Estudante de graduação & 2015 \\
\hline A7 & 26 & F & Estudante de gradução & 2015 \\
\hline A8 & 23 & F & Estudante de graduação & 2015 \\
\hline A9 & 22 & F & Estudante de graduação & 2017 \\
\hline A10 & 24 & F & Estudante de graduação & 2017 \\
\hline A11 & 25 & M & Estudante de gradução & 2017 \\
\hline A12 & 22 & F & Estudante de graduação & 2017 \\
\hline
\end{tabular}

Figura 2: Perfil dos Entrevistados

Fonte: Elaborada pelos autores (2018).

Tal fenômeno foi analisado com base em entrevistas com questões abertas correspondendo ao objetivo do presente artigo, fundamentado no processo de institucionalização de Tolbert e Zucker (1999), entrevistas estas realizadas com os doze estudantes que atuaram como coordenadores do PAI nos anos de 2015-2017. Para Manzini (1990), a entrevista semiestruturada está focalizada em um assunto sobre o qual se confeccionou um roteiro com perguntas principais, complementadas por outras questões inerentes às circunstâncias momentâneas à entrevista. Para 0 autor, esse tipo de entrevista pode fazer emergir informações de forma mais livre e as respostas não estão condicionadas a uma padronização de alternativas. Ressalta-se que 0 instrumento de pesquisa foi validado com três ex-coordenadores do PAl e, após as devidas considerações do mesmo, as entrevistas foram descartadas como um pré-teste.

Questionários, atas de reuniões, listas de participantes do programa, lista de estudantes estrangeiros que foram ajudados pelo programa, manual com o treinamento dos participantes, editais de processo seletivo, planejamento de atividades e publicações sobre o PAl compõem os documentos levantados. Por fim, a pesquisa 
de campo coletou dados primários por meio de entrevistas com os estudantes envolvidos no programa como coordenadores de atividades entre os anos de 2015 até 2017. Visando alcançar o objetivo deste trabalho por meio de uma exploração do campo estudado, foram realizadas, em julho e agosto de 2017, doze entrevistas de uma média de 20 minutos, de roteiro semiestruturado, cujos sujeitos de pesquisa participam como atores no processo de institucionalização do Programa de Apoio ao Intercambista (PAl).

0 roteiro de entrevistas é composto por um modelo com sete perguntas, o qual foi aplicado aos 4 coordenadores de atividades atuais (referente ao ano de 2017) e aos 8 ex-coordenadores do PAl (2015-2016), perguntas estas correspondentes ao objetivo deste trabalho. $O$ roteiro de entrevista foi estabelecido conforme a Figura 3:

\begin{tabular}{|c|c|}
\hline Categorias & $\begin{array}{ll} & \text { Perguntas } \\
\end{array}$ \\
\hline $\begin{array}{l}\text { a) Evolução dos fatores determinantes } \\
\text { para a constatação da fase de pré- } \\
\text { institucionalização do programa ao } \\
\text { longo desses três anos (Variável: } \\
\text { Habitualização) }\end{array}$ & $\begin{array}{l}\text { Em quais processos do PAl você atua (atuou)? Esses processos seguem } \\
\text { algum modelo e forma preestabelecidos? } \\
\text { Como você avalia a evolução das atividades do Programa do Apoio ao } \\
\text { Intercambista durante o ano que você atuou como coordenador de } \\
\text { atividades? }\end{array}$ \\
\hline $\begin{array}{l}\text { b) Fatores de entraves do avanço para } \\
\text { a fase de objetivação (Variável: } \\
\text { objetivação) }\end{array}$ & $\begin{array}{l}\text { Você buscou informações sobre outros projetos de suporte aos estudantes } \\
\text { estrangeiros em outras universidades brasileiras ou estrangeiras? Por quê? } \\
\text { Quais atividades você destacaria como atividades consolidadas e eficientes } \\
\text { do PAl? E quais as que você considera como fracas e que necessitam uma } \\
\text { melhor aplicação? }\end{array}$ \\
\hline $\begin{array}{l}\text { c) Fatores que coadjuvam à fase de } \\
\text { objetivação do programa (Variável: } \\
\text { objetivação) }\end{array}$ & $\begin{array}{l}\text { Na sua opinião, o que melhoraria se o PAl fosse institucionalizado? E o que } \\
\text { pioraria? } \\
\text { Para os futuros coordenadores do PAl, o que você vai deixar consolidado no } \\
\text { programa? E o que você vai deixar para ser implementado? }\end{array}$ \\
\hline
\end{tabular}

Figura 3: Roteiro de entrevista seguindo o modelo de institucionalização de Tolbert e Zucker (1999) Fonte: Elaborada pelos autores (2018)

Transcritos após gravação em áudio, os dados coletados nas entrevistas foram analisados por meio da técnica de análise de conteúdo. Os dados primários foram coletados por meio das entrevistas e tratados por meio de análise de conteúdo de Bardin (2016). Segundo o autor, trata-se de "um conjunto de técnicas de análise das comunicações visando obter por procedimentos sistemáticos e objetivos de descrição do conteúdo das mensagens indicadores (quantitativos ou não) que permitam a inferência de conhecimentos relativos às condições de produção/resseção (variáveis inferidas) destas mensagens". Esta técnica propõe analisar o que é explícito no texto para obtenção de indicadores que permitam fazer inferências. Para o tipo de entrevista em apreço, é indicada a modalidade de análise qualitativa (procura-se analisar a presença ou a ausência de uma ou de várias características do texto).

\section{ANÁLISE DOS RESULTADOS}

Depois de uma primeira leitura das entrevistas a serem analisadas, pretendeu-se destacar trechos da entrevista transcrita, o que se passou a apresentar de acordo com:

1. Percepção sobre os fatores ligados à fase de objetivação;

2. Valorização da evolução do Programa de Apoio ao Intercambista (PAl) nos últimos anos;

3. Percepção dos agentes limitadores da evolução do programa.

\subsection{Percepção sobre fatores ligados à fase de objetivação}

No que diz respeito à verificação da evolução dos fatores determinantes na constatação da fase de préinstitucionalização do programa ao longo desses três anos, verifica-se a recorrência entre os entrevistados das seguintes palavras: "Padronização", "Padrão", "Modelo", "Regra", "Estrutura". "Controle", "Demanda", "Atividades", "Ajustes", principalmente nos entrevistados A10, A5, A4 e A3, com a frequência de pelo menos duas dessas 
palavras em cada uma das respostas desses quatro entrevistados. Para enfatizar a fase de pré-institucionalização do PAl, uma das atuais coordenadoras do PAI (A10) destaca:

Os padrinhos/madrinhas seguem um modelo apresentado nos treinamentos. Esse modelo se refere ao modo básico de como devemos receber os intercambistas. Anteriormente, esse modelo era bastante flexível, pois variava de acordo com as novas necessidades demandadas pela Universidade e pelos estudantes estrangeiros. Agora, como já foram identificadas as principais demandas, o modelo já segue cada vez mais padronizado e uniforme. (A10)

Para ressaltar a evolução dos fatores determinantes da fase de pré-institucionalização, um excoordenador do PAl (A5) enfatiza:

Quando atuei na coordenação do programa, estávamos trabalhando na estruturação dos modelos e das atividades a serem executadas. Havia sempre algo novo para acrescentar ou para ajustar e fomos mapeando o que seria modificado até chegar a um modelo que fosse eficiente no suporte ao estudante estrangeiro. O maior problema que tivemos foi estabelecer alguma forma de controle das atividades realizadas. (A5)

O processo de pré-institucionalização, segundo Tolbert e Zucker (1999), envolve a criação de configurações estruturais em resposta às demandas específicas do contexto em que a organização se insere, assim como a formalização dessas configurações na organização, ou no conjunto de organizações que possuem similaridades.

A partir dessa definição e da análise das respostas dos entrevistados, pode-se constatar que, antes 0 programa adaptava suas atividades de acordo com as demandas da universidade e dos estudantes estrangeiros, verificando assim uma ausência de padronização dos processos realizados pelo programa, assim como a inexistência de um controle estruturado das atividades consolidadas. Percebe-se também a evolução desses fatores que determinaram a fase de pré-institucionalização do programa, pois atualmente ele já se apresenta mais estruturado e trabalha na definição de uma forma de controle eficiente das atividades desenvolvidas de maneira mais padronizadas.

\subsection{Valorização da evolução do Programa de Apoio ao Intercambista (PAl) nos últimos anos}

Em relação à valorização da evolução do PAI nos últimos, percebe-se a frequência das seguintes palavras entre os entrevistados: "Expansão", "Evolução", "Crescimento", "Controle", "Comparação", com destaque entre os entrevistados A11, A1, A4, A6 e A7, com a frequência de pelo menos uma dessas palavras aparecendo mais de duas vezes em seus respectivos discursos.

Tolbert e Zucker (1999) definem objetivação ou semi-institucionalização como a fase que envolve o desenvolvimento de um consenso entre os adotantes a respeito do valor da estrutura, além da sua adoção crescente com base nesse consenso que emerge por meio de dois mecanismos: o monitoramento, realizado pela organização nos seus concorrentes, o qual avalia os riscos de adoção de uma nova estrutura; a teorização, que atribui à estrutura uma legitimidade cognitiva e normativa geral. Diante disso, destaca-se a seguinte colocação de um dos atuais coordenadores do PAI (A11):

\footnotetext{
A meu ver, a melhor maneira de se avaliar a evolução do programa, além do modo quantitativo, é o sentimento de que a atuação do programa e sua importância no contexto social da universidade vem sendo mais valorizado pelos alunos internos da UFC. Entretanto, o fato do programa ter surgido a partir da iniciativa dos alunos para a Universidade é um fato que torna a expansão do programa pela Universidade ainda mais desafiante, pois o programa tem que contar muito com a proatividade dos envolvidos. Apesar do programa contar com a participação de estudantes de vários campus e cursos da UFC, o programa ainda está vinculado oficialmente somente a uma única diretoria da UFC. (A11)
}

Adicionalmente a esse último relato, destaca-se a resposta de um ex-coordenador do PAI que atuou no programa em 2016 (A1): 
Nos últimos anos conseguimos trabalhar em parceria bastante produtiva com o PROINTER, porém o fato do PAI ser vinculado somente à diretoria da FEAAC acaba limitando a expansão do programa pela UFC. A maioria dos intercambistas e dos padrinhos vem de outros cursos situados em campus diferentes, mas as atividades do programa ainda permanecem muito concentradas na FEAAC. Como o PAI ainda não possui uma sala própria, dificultou para realizarmos nossas reuniões, pois sempre ficamos dependentes da disponibilidade das salas da FEAAC. Se o programa tivesse uma sala própria seria mais fácil controlar as atividades dos padrinhos. (A1)

\subsection{Percepção dos agentes limitadores da evolução do programa}

Em relação aos entraves do avanço para a fase de objetivação, fica evidenciado por meio das entrevistas que o programa continua sua expansão pela universidade, mas a ausência de uma estrutura física destinada às atividades do programa constitui um dos principais entraves do avanço para a fase de objetivação. Nas entrevistas tornaram-se bastante recorrentes as palavras "Concentração", "FEAAC", "Reuniões" "Sala", "Limitadas" entre os entrevistados $A 1, A 9$, $A 8$ e $A 11$, com uma frequência de pelo menos duas dessas palavras em cada entrevista.

A ausência de uma estrutura física definida compromete o monitoramento das atividades do programa que, atualmente, de acordo com os entrevistados, trabalha na definição de instrumentos de controle das atividades desenvolvidas. Outro entrave observado nas entrevistas é o fato de mesmo a maioria dos participantes do programa ser estudante de outros cursos da UFC, o programa apresenta oficialmente vínculo somente com uma única diretoria da universidade, o que passa a ser um agente limitador da expansão do programa por toda a Universidade.

Diante disso, prossegue-se com o terceiro objetivo específico, relacionado aos fatores que coadjuvam à fase de objetivação do programa, destaca-se a resposta de uma ex-coordenadora do PAI (A2):

A maioria dos estudantes escolhidos para serem padrinhos são também ex-intercambistas do programa Ciências sem fronteiras, e muitos deles voltaram para o Brasil com muitas ideias interessantes, pois a grande maioria recebeu suporte nas universidades que realizaram intercâmbio. É muito interessante, pois através dessas experiências no exterior eles ajudam a gente, da coordenação, com ideias que podemos aplicar no PAl. Muitos se sentem muito satisfeitos em poder retribuir de alguma maneira a ajuda que receberam durante o intercâmbio e nós da coordenação sempre valorizamos muito isso. (A2)

Um dos atuais coordenadores do PAI ainda ressalta que:

Como também já fiz intercâmbio, para mim ficou bem claro a importância do suporte da universidade, principalmente nas primeiras semanas, onde tudo é novidade. No PAl, tento sempre aplicar o que aprendi durante o intercâmbio. Na Universidade que eu fui, eles tinham o próprio programa de suporte aos estudantes estrangeiros, era bastante oficial e organizado e quero muito trazer para o PAl essa imagem oficial e bem estruturada. Muitas das atividades que realizamos no PAl são bem parecidas com a da universidade que fiz meu intercâmbio.

Ainda, sobressai-se a colocação de outra atual coordenadora do PAI (A12):

0 aprendizado com a gestão das atividades do PAl é bastante enriquecedor, tenho a possibilidade de pôr em prática muito do que tenho aprendido nas aulas no curso de administração que estudo. Estamos todos muito felizes com o alcance que o PAl tem tido. Esse ano, conseguimos que nosso trabalho chegasse até ao Reitor da UFC. Ficamos muito feliz com esse reconhecimento e queremos continuar trabalhando para que o programa cresça cada vez mais e sirva como exemplo para outras universidades brasileiras. (A12)

Diante desses relatos, passa a ser evidenciado que um dos fatores que coadjuva à fase de objetivação do PAl é o monitoramento por meio da comparação com o suporte aos estudantes estrangeiros feito por outras universidades brasileiras ou estrangeiras. Nas entrevistas, foi possível verificar a preocupação dos envolvidos no PAI com a aplicação de boas práticas oriundas das experiências de estudantes participantes do programa. A

Revista Alcance - Eletrônica - vol. 25 - n. 3 - Set./Dez. 2018 
comparação com as atividades de outras universidades é um ponto de destaque no avanço de préinstitucionalização para semi-institucionalização do Programa de Apoio ao Intercambista.

A definição de mudanças nas atividades do programa e, consequentemente, a mudança na sua estrutura, em função de comparação com as atividades desenvolvidas, é outro ponto importante. O PAl iniciou suas atividades no caminho inverso do que acontece com a maioria das universidades brasileiras e estrangeiras, pois começou a partir da iniciativa dos estudantes para a Universidade e, normalmente, o suporte aos estudantes estrangeiros parte da iniciativa da Universidade para os estudantes. Diante da análise das entrevistas, é perceptivel a preocupação em consolidar as atividades bem executadas, inclusive com a intenção de seguir como modelo para outras instituições, como também eliminar práticas que possam enfraquecer o programa e possivelmente levar à sua extinção, já que, até então, o programa não conta com um apoio sólido institucional, o que dificulta a sobrevivência do programa. A melhor visualização dos resultados é demonstrada como resumo na Figura 4.

\begin{tabular}{|c|c|c|c|c|}
\hline $\begin{array}{l}\text { Identificação } \\
\text { na análise de } \\
\text { conteúdo }\end{array}$ & $\begin{array}{l}\text { Palavras- } \\
\text { chaves mais } \\
\text { recorrentes } \\
\text { nas } \\
\text { entrevistas }\end{array}$ & Sujeito & $\begin{array}{l}\text { Identificação da fase de } \\
\text { institucionalização no } \\
\text { modelo de Tolbert e Zucker } \\
\text { (1999) }\end{array}$ & $\begin{array}{l}\text { Definição no modelo de Tolbert e } \\
\text { Zucker (1999) }\end{array}$ \\
\hline $\begin{array}{l}1 \text { Percepção } \\
\text { sobre os fatores } \\
\text { ligados à fase } \\
\text { de objetivação }\end{array}$ & $\begin{array}{l}\text { "Padroniza- } \\
\text { ção", } \\
\text { "Padrão", } \\
\text { "Modelo", } \\
\text { "Regra", } \\
\text { "Estrutura". } \\
\text { "Controle", } \\
\text { "Demanda", } \\
\text { "Atividades", } \\
\text { "Ajustes" }\end{array}$ & $\begin{array}{l}\text { A10 } \\
\text { A5 } \\
\text { A4 } \\
\text { A3 }\end{array}$ & $\begin{array}{l}\text { Fase de Objetivação em que } \\
\text { há uma passagem do estágio } \\
\text { pré-institucional para o semi- } \\
\text { institucional. }\end{array}$ & $\begin{array}{l}\text { "Ocorre um desenvolvimento de certo } \\
\text { grau de consenso social entre os } \\
\text { decisores da organização a respeito do } \\
\text { valor da estrutura e a crescente adoção } \\
\text { pelas organizações com base neste } \\
\text { consenso". }\end{array}$ \\
\hline $\begin{array}{l}2 \text { Valorização da } \\
\text { evolução do } \\
\text { Programa de } \\
\text { Apoio ao } \\
\text { Intercambista } \\
\text { (PAl) nos } \\
\text { últimos anos }\end{array}$ & $\begin{array}{l}\text { "Expansão", } \\
\text { "Evolução", } \\
\text { "Crescimen-to } \\
\text { Controle" } \\
\text { "Compara-ção }\end{array}$ & $\begin{array}{l}\text { A11 } \\
\text { A1 } \\
\text { A4 } \\
\text { A6 } \\
\text { A7 }\end{array}$ & $\begin{array}{l}\text { Transição da fase de pré- } \\
\text { institucionalização para semi- } \\
\text { institucionalização }\end{array}$ & $\begin{array}{l}\text { "Predomina o monitoramento, realizado } \\
\text { pela organização nos seus } \\
\text { concorrentes". }\end{array}$ \\
\hline $\begin{array}{lr}3 & \text { Percepção } \\
\text { dos agentes } \\
\text { limitadores da } \\
\text { evolução do } \\
\text { programa }\end{array}$ & $\begin{array}{l}\text { "Concen- } \\
\text { tração", } \\
\text { "FEAAC", } \\
\text { "Reuniões" } \\
\text { "Sala" , } \\
\text { "Limitadas" }\end{array}$ & $\begin{array}{c}\text { A1 } \\
\text { A9 } \\
\text { A8 } \\
\text { A11 }\end{array}$ & $\begin{array}{l}\text { Fase de } \\
\text { institucionalização }\end{array}$ & $\begin{array}{l}\text { "Nesta etapa, primeiramente, identifica- } \\
\text { se um problema de insatisfação ou de } \\
\text { fracasso organizacional, típico de um } \\
\text { determinado campo organizacional e de } \\
\text { reconhecimento público". }\end{array}$ \\
\hline
\end{tabular}

Figura 4: Resumo da Análise de Conteúdo

Fonte: Elaborado pelos autores (2018).

Algumas das constatações da análise de conteúdo das entrevistas são confirmadas pelos resultados da análise documental realizada. Por meio de uma divisão temporal em dois períodos, 2014-2015 e 2016-2017, percebe-se que o programa já apresentava documentos padronizados no primeiro período avaliado; e no segundo período os documentos prosseguiram com a mesma forma de padronização, entretanto alguns documentos existentes no primeiro período não tiveram continuidade no segundo período e alguns documentos foram adicionados, seguindo a mesma formatação dos outros.

Por meio dessa análise documental, verificou-se que os fatores determinantes da fase de préinstitucionalização enfraqueceram ao logo desses 3 anos. O programa anteriormente carecia de instrumentos de controle de suas atividades e essa falta exercia influência em sua estrutura, tornando-a mais vulnerável e definindo-a na fase de pré-institucionalização, segundo o modelo de Tolbert e Zucker (1999). Percebe-se que, ao longo desses 3 anos, o programa verificou a necessidade de mudanças e criou vários instrumentos de monitoramento de suas atividades. 
Para finalizar, Tolbert e Zucker (1999) afirmam que a fase de sedimentação se caracteriza pela propagação da estrutura por um grupo de atores, considerados como adotantes adequados, e por sua perpetuação por um período consideravelmente longo de tempo, sendo considerado o estágio de total institucionalização. 0 Programa de Apoio ao Intercambista, apesar de ter avançado ao longo desses três anos e adequado à sua estrutura com o desenvolvimento de instrumentos de controle e monitoramento, além da consolidação de diversas das suas atividades, ainda não apresenta fatores relevantes ligados à fase de sedimentação.

\section{CONSIDERAÇÕES FINAIS}

Com base na análise de conteúdo, a pesquisa atingiu seu objetivo geral de analisar os fatores que configuram o programa na fase de pré-institucionalização, segundo o modelo de Tolbert e Zucker (1999). Dessa forma, constatou-se que houve uma evolução dos fatores que determinaram a fase de pré-institucionalização do programa, pois, conforme as entrevistas, foi percebido que o PAl já se encontra mais estruturado e apresenta instrumentos de controle mais presentes, buscando a padronização das atividades e a consolidação de sua estrutura.

Concomitantemente, percebeu-se que um dos principais fatores que causa entraves à fase de objetivação do programa é a falta de uma estrutura física, pois isso prejudica o controle das atividades envolvidas. Além disso, foi ressaltado que o fato do PAl ser vinculado apenas a uma diretoria da universidade é considerado um fator limitador à sua expansão pela Universidade.

Não obstante, constatou-se ainda que um dos fatores que coadjuva à fase de objetivação de entrevistas é o monitoramento da evolução do programa por meio da comparação com o suporte aos estudantes estrangeiros feito por outras universidades brasileiras ou estrangeiras. Além disso, conforme visto nas entrevistas e na análise documental, os três pressupostos estabelecidos no estudo foram confirmados.

Com a análise de dados referente ao estudo, os pesquisadores perceberam que essa visão ficou limitada apenas aos coordenadores e aos ex-coordenadores do PAl. Assim, sugere-se que sejam feitas pesquisas futuras com uma coleta de dados mais ampla, incluindo uma amostra dos estudantes que recebem o apoio do PAl e outros participantes do programa que atuaram como padrinhos dos intercambistas, bem como a percepção de gestores, professores e servidores da Universidade sobre o PAl e, também, a expansão da pesquisa por meio da comparação com outros programas de suporte a estudantes estrangeiros, já institucionalizados, de universidades brasileiras, comparando o desempenho desses programas e os impactos para as Universidades. Para finalizar, como possível aprofundamento dessa pesquisa, sugere-se expor a evolução de processo de institucionalização do PAl em outros modelos de institucionalização.

\section{REFERÊNCIAS}

Aguiar, I. C., Lessa, B. S., Marino, P. B. L. P., Braga, D. S. G., Cabral, A. C. A., \& Santos, S. M. D. (2015). The Institutionalization Process of the Support Program for Exchange Students from the Federal University of Ceará. Revista Alcance, 22(3), 379-393.

Andrade, A. M. J., \& Teixeira, M. A. P. (jun. 2009). Adaptação à universidade de estudantes internacionais: um estudo com alunos de um programa de convênio. Rev. bras. orientac. Prof., São Paulo, 10(1), 33-44.

Bardin, L. (2016). Análise de conteúdo. São Paulo: Edições 70.

Bauer, M. W., \& Gaskell, G. (2002). Pesquisa qualitativa com texto, imagem e som: um manual prático.

Petrópolis: Vozes.

Beckert, J. A. (Sept. 1999). Entrepreneurs, and institutional change. The role of strategic choice and institutionalized practices in organizations. Organization Studies, 20(5), 777-799.

Berger, P. L., \& Luckmann, T. (1996). A construção social da realidade: tratado de sociologia do conhecimento. Petrópolis: Vozes.

Bogdan, R., \& Biklen, S. (2010). Investigação Qualitativa em Educação: Uma Introdução à Teoria e aos Métodos. Porto: Porto Editora.

Burns, J. (2000). The dynamics of accounting change: inter-play between new practices, routines, institutions, power and politics. Accounting, Auditing and Accountability Journal, 13, 566-596.

Revista Alcance - Eletrônica - vol. 25 - n. 3 - Set./Dez. 2018 
Carvalho, C. A. P., Vieira, M. M. F., \& Lopes, F. (2003). Contribuições da perspectiva institucional para análise das organizações. In: III EnANPAD - Encontro Nacional de Pós-Graduação em Administração, Foz do Iguaçu.

Chun, J. H. (2016). Can CAMPUS Asia program be a next ERASMUS? The possibilities and challenges of the CAMPUS Asia program. Asia Europe Journal, 14(3), 279-296.

Dimaggio, P. J., \& Powell, W. W. (1983). The iron cage revisited: institutional isomorphism and collective rationality in organizational fields. American Sociological Review, 48, 147-160.

Ferreira, J. M. C., Gesaca, S. F., \& Jerônimo, H. M. (2001). Teorias ecológicas e sociocognitivas. In Ferreira, J. M. C., Neves, J., \& Caetano, A. Manual de psicossociologia das organizações. Lisboa: Escolar Editora.

Greenwood, R., Oliver, C., Sahlin, K., \& Suddaby, R. (2008). Introduction. In Greenwood, R., Oliver, C., Sahlin, K., \& Suddaby, R. The Sage handbook of organizational institutionalism (1-46). Los Angeles, Califórnia: SAGE Publications Lts.

Knight, J., \& De Wit, H. (1995). Strategies for internationalization of higher education: historical and conceptual perspectives. In De Wit, H. (Org.). Strategies for internationalization of higher education a comparative study of Australia, Canada, Europe and United States of America (5-33). Amsterdam: European Association for International Education.

Knight, J. (2004). Internationalization Remodelled: Definition, Approaches, and Rationales. Journal of Studies in International Education, Sage Publications, 8(1), 5-31.

Laville, C., \& Dionne, J. (1999). A construção do Saber. Manual da metodologia da pesquisa em ciência humanas. Belo Horizonte: UFMG.

Lima, B. C. C., Cabral, A. C. A., Pessoa, M. N. M., \& Santos, S. M. (2012). Economia criativa no Ceará: um estudo da institucionalização do campo do humor. In: XXXVI EnANPAD. Rio de Janeiro.

Lima, T. C. A., Cabral, A. C. A., Pessoa, M. N. M., Santos, S. M., \& Nascimento, D. C. (jan.jun. 2011). A institucionalização das práticas de responsabilidade social: um estudo da companhia de água e esgoto do Ceará. Revista Contemporânea de Economia e Gestão, FEAAC: Fortaleza, 9(1).

Machado-Da-Silva, C., Fonseca, V. S., \& Crubellate, J. M. (2005). Estrutura, agência e interpretação: elementos para uma abordagem recursiva do processo de institucionalização. Revista de Administração Contemporânea, 9(1), 9-39.

Miura, I. K. (2006). O processo de internacionalização da Universidade de São Paulo: um estudo de caso de três áreas do conhecimento. Tese (Livre Docência) - Faculdade de Economia, Administração e Contabilidade da Universidade de São Paulo, Ribeirão Preto.

Moraes, M. R. de. (2001). As relações intergovernamentais na República Federal da Alemanha (383). São Paulo: Fundação Konrad Adenauer.

Morosini, M. C. (2006). Estado do conhecimento sobre internacionalização da educação superior: conceitos e práticas. Educar, Curitiba, 28, 107-124.

Muller, C. V. (2013). O processo de internacionalização do ensino superior: um estudo de caso da Universidade Federal do Rio Grande do Sul. Dissertação (Mestrado em Relações Internacionais), Programa de Pósgraduação em Relações internacionais, Instituto de Filosofia e Ciências Humanas, Universidade Federal do Rio Grande do Sul.

Penha, E. D. S., Alexandre, M. M., Cabral, A. C. A., Santos, S. M., \& Pessoa, M. N. M. (2013). Empresas Juniores: O Processo de Institucionalização em Universidades Públicas do Ceará. In: IV Encontro de Ensino e Pesquisa em Administração e Contabilidade, Brasilia.

Peña, A. P. T., \& Soares, J. R. R. (2017). Student mobility and differentiated access to Spanish citizenship: the case of Mexicans, Colombians and Brazilians in Galicia. Foro de Educación, 15(22).

Qiang, Z. (2003). Internationalization of higher education: towards a conceptual framework. Policy Futures in Education, 1(2), 248-270.

Quinello, R. (2007). A teoria institucional aplicada à administração. São Paulo: Novatec.

Scott, W. R. (1987). The adolescence of institutional theory. Administrative Science Quarterly, 32(4), 493- 511.

Italo C. Aguiar, Barbara S. de Menezes, Bruno de S. Lessa, Augusto Cezar de A. Cabral e Sandra M. dos Santos 
Scott, W. R. (2001). Institutions and organizations. Thousand Oaks-CA: Sage.

Silveira, M. (2017). Acolhimento do aluno estrangeiro - o aspecto humano na gestão. In: $7^{a}$ Conferencia Forges, Portugal.

Souza, N.Q. (2010). Institucionalização das ações de responsabilidade social corporativa: um estudo em universidades comunitárias gaúchas. Dissertação, Universidade Regional do Noroeste do Estado do Rio Grande do Sul - UNIJUÍ, Rio Grande do Sul.

Stromquist, N. P. (2007). Internationalization as a response to globalization: Radical shifts in university environments. Higher Education, 53(1), 81-105.

Tolbert, P. S., \& Zucker, L. G. (1999). A institucionalização da teoria institucional. In: Clegg, S., Hardy, C., \& Nord, W. (Org.). Handbook de estudos organizacionais (vol. 1). São Paulo.

UFC, Plano de Internacionalização. (2017). Plano Internacionalização da Universidade Federal do Ceará. Recuperado em 12 nov., 2017, de http://www.ufc.br/images/_files/a_universidade/plano-internacionalizacaoufc/plano-internacionalizacao-ufc.pdf.

Wen Yu, H. (2009). Studying Abroad as a Possibility of Development: Exploring the Educational Meaning of Studying Abroad from the Life Stories of Six Taiwan Female Students in Germany. Journal of Research in Education Sciences, 54(3), 109-138. 